\title{
PUBLIC-PRIVATE PARTNERSHIP - A NEW PERSPECTIVE FOR THE TRANSITION COUNTRIES
}

\author{
D. Dechev* \\ Faculty of Economics, University of Economics - Varna, Varna, Bulgaria
}

\begin{abstract}
Public-private partnerships (PPP) are a new perspective for development of the public sector by using the experience of the private sector. The state is facing challenges that require implementation of flexibility and diversification of activities as well as looking for new opportunities to finance large infrastructural projects. One of the possible ways to implement the projects is through public-private partnership. This article aims to define the basic criteria to be met by a successful PPP, as well as, to generate recommendations for improving the environment for public-private partnership and for increase of the efficiency of this type of cooperation. To achieve the objective of this article, a definition of PPP has been drawn up, the regulatory framework in Bulgaria has been studied and advantages and disadvantages of public-private partnerships have been specified based on examples from the countries of Central and Eastern Europe.
\end{abstract}

Key words: public partner, private partner, capital expenditures, economic risks, increased efficiency, PPP contracts.

\section{INTRODUCTION}

In recent decades, development of public relations in Central and Eastern Europe, including in Bulgaria, are historically marked by significant intensity. The reasons for this are dictated by the changing geopolitical relations, development and transition from a planned to a market-oriented economy and by the opportunities for access to European markets and those outside of Europe. Reallocation of capital and change in the structure of economic management create conditions for new forms of ownership governance and new capital structure as a manifestation of the state, through implementation of its main obligations related to its function. A typical example in this aspect is the establishment of public-private partnerships (PPP).

In fulfilment of its functional obligation, the public sector during the transition went through various forms of expression, searching for the most appropriate way to reach the

\footnotetext{
*Correspondence to: Daniel. Dechev, University of Economics Varna, 77 Kniaz Boris I blvd, Varna, Bulgaria, Postal code: 9000, e-mail:

Daniel.dechev@ue-varna.bg tel. +359884301732.
}

implementation of PPP. This way is supposed to find the balance across sectors and is expected to limit the risk of failure of the goals and objectives.

In incorporating and globalizing Europe, public- private partnerships are considered as a new perspective for the development of the public sector through the experience of the private sector. Behavioural strategy of the business, however, is the result of a market economic dependence which is very different from the priorities of the subject - the public sector. In this sense, public-private partnership (PPP) is the combining of two different systems that operate based on different mechanisms and apply different practices in objectives implementation. Materialization of experiences in one or the other sector that have been accumulated in the opposite one involves additional risks and unknown aspects.

Representative functions of the administration that apply multiple ownership rights of all citizens to ensure their particularistic interests within the legal opportunities cannot develop a system for efficient economic resources management as well as inalienable corrective systems for every business organization, such 
as a risk management system due to missing or conflicting with the business environment incentives in the administrative nature of government (1).

However, the degree of development of the economies of Eastern Europe in terms of various forms of activities in the public sector face indispensable necessity dictated mostly by the inability for financial security to commitments to achieve the set objectives. This necessity is further related to introduction of new forms of financing and management of the public sector, due to the limited capacity of the state to meet the constantly increasing demands on the public sector and at the same time to exit of the dominant role of the sole executor of public functions.

\section{EXPOSE}

\section{Historical background}

The idea of public-private partnership dates back to the emblematic example marking the launch of PPP in Europe in the 19th century by materialization of the business strategy of Alfred Eiffel who designed and built the Eiffel Tower with his own funds against the right to issue tickets for its visitors in the course of 20 years ahead. As innovative thinking, this idea has gained more and more followers in the countries with developing economies. Thus, the PPP launch in Europe has been marked by a business idea that at this time and this place gave an example of an innovative approach to its market realization, establishing more effective methods for investment in the public interest (2)"by combining the benefits of public investment and private initiative."

This practice has been preserved up to now mainly in infrastructural projects funded either with public funds only or with private funds respectively. On long-term basis, such projects are often characterized by instability (3).

Bulgaria's accession to the European Union (EU) has put new challenges to the public sector which require application of flexibility and diversification of its activities as well as seeking new opportunities for funding and managing of large infrastructure projects. In response to the need to manage these processes, an administrative sector PPP has been established at the Ministry of Finance in 2005.

The PPP implementation in Bulgaria as a method for investments which generates and manages significant financial resources requires precise definition of 'What is a publicprivate partnership "?

\section{Defining the concept of Public Private Partnership (PPP)}

In general, public private partnership is defined as a form of cooperation between public authorities and the business world which aims to provide financing, construction, renovation, management or maintenance of infrastructure, or the provision of a service.

One of the leading definitions of the International Monetary Fund (IMF) defines public-private partnerships as agreements under which the private sector provides assets and services that are traditionally provided by the state, thus further narrowing the scope of PPP, indicating that PPP usually is an agreement for the design, construction, financing and operation of infrastructure. (4)

The definition of PPP in Bulgaria, according to the Law on public- private partnership effective as of 01.01.2013 is "long-term cooperation between one or more public partners on the one hand, and one or more private partners, on the other hand, to carry out activities of public interest in achieving better value of invested public funds and risk allocation between the partners, which is subject to the conditions and provisions of this Law."(5)

Under this definition, award of design, funding and implementation of activities to the private sector is motivated by the belief that this will lead to higher efficiency of the service provided by the implementation of private sector's experience in management of both investment and risk related to generation of capital. Thus, in case of PPP, the state purchases an end product or final service from the private investor, and in this way transfers to the private investor the responsibility for service provision to citizens who are end-users of the infrastructure.

Regardless of the responsibilities allocation between the private and public sector, at the end the public sector maintains or restores its ownership of the infrastructure - subject of PPP, and the capital invested by the private investor is restored under a contract with the competent public authority, or through a fee that shall be collected from the users of this infrastructure (6).

Implementation of PPP in different countries has national specificities that contribute to the 
concept of public-private partnership, respectively to the definition of PPP. Taken into consideration, these specificities provide the most correct characteristic of the concept through its practical implementation on the basis of the experience of the various countries in the public sector. Therefore, each country has its own concept, i.e. definition of publicprivate partnership that fit best into its own legislations system and strategic perspectives.

Definition, development and implementation of PPP in Bulgaria are reflected in the laws, regulations and other documents. Worth to be mentioned are the following ones: Law on Public-Private Partnership and the adjacent Implementing Regulations of the Law; Concessions Act and its adjacent Implementing Regulations ; Law on Public Procurement; State Property Law; Municipal Property Act; Law on Local Self-Government and Local Administration; Ordinance on the Conditions and Procedures for Planning and Criteria for Inclusion of Projects for PublicPrivate Partnership in the Operational Plan and the Implementation Program of the Municipal Development Plan; Methodological Guidelines for Public-Private Partnership - first and second edition; Guidance on the Preparation of Financial model of PPP; Manual for CostBenefits Analysis of Investment Projects issued by the European Commission, Directorate-General "Regional Policy", July 2008 (7) . This conglomerate of legal and administrative tools defines an important factor impacting negatively on the structuring and implementation of PPP in Bulgaria - the frequent changes of laws and regulations, and the lack of timely adaptation and synchronization between them. This destructive effect is reinforced by the lack of mechanisms for adaptation of existing contracts for PPP.

In relation to above mentioned legislation, as public-private partnership can be considered all agreements with following characteristics: a relatively long duration of the contract between public institutions and private companies between 10 and 35 years contractual period ; financing of investment is at least partially on the account of the private partner, but payments are envisaged by the public sector or by users throughout the term of the contract; design, construction and maintenance of the object of the contract is undertaken by the private partner; risks associated with the project are divided between the two parties; subject to negotiation can be investments in both the Republican transport infrastructure
DECHEV D.

(roads, bridges, airports) and municipal infrastructure (waste treatment plants, electricity and water supply) as well as infrastructure related to rendering of educational, cultural and health services and sports facilities (8).

A better management of existing assets by the PPP limits the need for investment in new ones which is an essential motivation for PPP implementation. At the same time, it leads to reduction of the administrative and financial burden on public finances in terms of delivery of the services. This changes the discourse of the public sector in its function of direct service provider, and modifies it as a body, authorizing and coordinating the activities of other contractors, including non-governmental organizations, consumers' and citizens' associations and society as a whole.

This new role requires also the new function of state and local government to adequately protect the interests of the taxpayers, which can only be achieved through the integration or accumulation of additional structures in the public sector that follow the pattern of the business model of private sector, and perform control functions. Their function should be reflected in the implementation of adequate financial control over payments with the private sector regarding the achievement of preliminary set quantitative and qualitative criteria, as well as to observe the risks' management in working together. In their new role as "consumers" of the service, the government or the local authorities should be entitled to financial restrictions in case of infringement of the requirements set. The change in the roles distribution does not lead to elimination of functions in the process but only to their transfer as responsibility to the other side. This transfer requires the private sector to take a number of functions, thus to be defined as an active part in this type of partnership, facilitating to a high extent the role of the state institutions. As result of this, the definition of the concept of PPP in Bulgaria will acquire the necessary national specifics.

\section{Advantages that facilitate implementation of the PPP}

Based on analysis of the reasons for the need to implement a public-private partnership that made it popular in Europe, they can be synthesized in the following groups:

- attraction of private capital for the implementation of needed investments due to lack of public funds, or in compliance 
with the rules for fiscal discipline within the European Union;

- increasing the efficiency of public services and resources invested in them;

- transfer of risk to private partners in order to achieve its better management. (9)

Implementation of an investment through public-private partnership results in a decrease of the public capital expenditures, which in turn facilitates the Member States to meet the Maastricht criteria for levels of public debt and budget deficit. Partial funding and construction of assets by the private partner helps to enable the investment of public interest at the time that is needed, and to a certain extent eliminates the need for public funding for its implementation. This enabled the materialization of a number of large infrastructure projects such as "Trakia" highway in Bulgaria, the highways "M1 / M15" in Hungary, the highway "D1" in Slovakia. On their turn, public partners involved in PPP are committed to annual payments to the private investor or to providing guarantees for loans to private partners, i.e. financing of the project, although they do not directly provide funds to build the infrastructure. The recently introduced Law on Public-Private Partnership in Bulgaria provides similar conditions to establish PPP. According to Art. 3 (2) of this Law, PPP is established when following conditions are met:

- the public partner cannot provide funding for the activities of public interest, and this funding shall be wholly or partially undertaken by the private partner;

- through risks' allocation between the public and the private partner, a better value will be achieved for public money invested.

This fact defines PPP as a kind of a "credit card" for the state (10) - allowing for the implementation of investments today, at the cost of future payments which hides the corresponding financial risk for the public sector.

It is believed that the main reason for the implementation of PPP is the higher efficiency of the private sector in the management of investments. Competition in the private sector as well as taking part in the implementation risks for the investment by the private partner stimulate cost optimization of building assets under this investment. This motivation is reinforced by the fact that most PPP combine building of infrastructure with the option to maintain the investment object which allows to further reduce operating costs.

Compared with other traditional forms of contracting, PPP has a significant advantage in terms of the option to transfer risks from the public to the private sector. In this respect, risks allocation is one of the main elements of the contracting between the parties but also one of the main factors for emergence of problems in the implementation of commitments under the PPP contract.

For PPP purposes, risk can be defined as probability for occurrence of an event that would change the basic parameters of the project (usually costs, benefits and time-tables) compared to expect. There are risks associated with public-private partnerships which are exclusive to individual stages of its implementation, while others are typical for the entire life cycle of the PPP (11). Regardless of the stages on which they occur, risks may affect the interests of both partners as well as the interests of only one of the partners. According to scientific literature, and analyzing the most commonly practiced forms of PPP, these risks might be divided into three main groups:

- risks associated with the construction they mainly relate to infrastructural projects, and involve risk for building of the infrastructure within the agreed period, with agreed quality and specified characteristics. The risk here is usually borne by the private investor since under the PPP contract it includes building of infrastructure by the private partner;

- risks related to availability - relating to the risks associated with the provision of a public service. The partner responsible for the provision of a public service to its users must ensure equal access to services for all potential users as well as the quality of the service provided.

- risks associated with demand - these risks relate to the demand for the service provided. They are connected with the correlation between estimated demand for the service and the actual number of users.

These three main groups of risks are key determinants in the process of building of infrastructural projects .In PPP implementation, the public sector aims to transfer part or all of them to the private partner. In practice, however, the public sector is able only very difficult to transfer the responsibility for the DELIVERY and 
QUALITY of the service to be rendered, even though it appears in the role of "user" under PPP. Given this determination in the scientific analysis, the main emphasis is on three major fields of risks - commercial, economic and macroeconomic, without analysing the risk borne by the public sector.

Based on this, PPP does not remove the risks for the public sector. This type of partnership can limit the risks to which the public sector is exposed in certain aspects, but this partnership may also lead to exposure to new risks. Underestimation by the public sector of the risks associated with PPP leads to inappropriate risk-sharing, lack of rules for the transfer of the risks as well as to lack of mechanisms to control them by both the public and private partners.

Given the above characteristics and expectations of the effect of PPP, following benefits can be distinguished of its application in Bulgaria:

- problems of public interest are solved by attracting of private capital;

- it creates preconditions for higher involvement of business in the long term;

- with the resources released, the public sector has an additional opportunity to apply social important policies;

- preconditions are created for modernization and optimization of public services' quality.

However, PPP represent a compromise between production and allocation efficiency. These agreements would increase public welfare, only if the benefits of increased production efficiency are higher than the losses of allocation efficiency.

\section{Disadvantages}

Despite the positive aspects of this kind of partnership between the private and public sectors, at a certain time-point transfer of assets to the private partner may cause partnership implementation to happen in a way that is beneficent only for a certain group of people or foreign interests, without ensuring better quality.

The analysis of specific public - private partnerships in Bulgaria and the countries of Central and Eastern Europe defines common weaknesses. Taking into account the particularities of national policies as well as the specifics of the national development of public-private partnerships, such analysis should define the reasons for this negative experience, and draw up conclusions about the
DECHEV D.

readiness of the countries in transition to start similar investments together with private partners.

\section{Lack of objective analysis}

One of the main difficulties in assessing the efficiency of public-private investment is due to the fact that in many cases the governments of the countries of Central and Eastern Europe launch the project with the aim to attract private capital for investment offering in return a commitment for later payments to this private investor. The experience of these countries shows that these payments are often unaffordable, and also vary in the course of project implementation. This is due to the lack of analysis of the objectives and replacement of the objective by the means, due to the replacement of the motivation, i.e. implementation of politically linked public duties - rendering of a specific service, without taking into account the amount of the investment, because of the ownership of the resource (funds) - it is not its owned but just managed.

Similar illustrative example of this is a publicprivate investment in the water supply of Zagreb, Croatia. The project cost has increased repeatedly - from176 million Euro in 2001, when it was decided to launch the project, to 299 million Euro in 2012, which drastically increased the cost of service to end users, but also led to increase of the obligations of the public partner to the private company. In 2004, industrial consumers refused to pay their bills for water treatment due to incorrectness of the private partner. Due to the fact that the public partner bears the risks associated with demand, the municipal council used public funds to repay part of these obligations. Experts estimate that by 2012 the public partner has paid to the private one 426 million Euro, and by the end of the contract in 2028 this amount will increase to 1.48 billion Euro.

Public-private partnership to build highways M1 / M15 in Hungary also ended with a substantial increase in the cost of the public partner, although under the original contract, the risks in demand for the service shall be borne by the private partner. Once it became clear that the planned traffic levels are unrealistic, in 1997 the contract was renegotiated: risks in the service demand were transferred to the public partner, and the private company received guarantee of $12 \%$ annual profit by payments from the state. In 1999 , (M15) and in 2004 (M1) highways were nationalized, thus proving that in all 
cases the public partner carries investments risks since it cannot afford to stop providing the public service.

Lack of independent economic and financial evaluation of the investment

These examples are indicative also for another major problem in the implementation of PPP connected to the lack of an independent economic and financial assessment of the investment. Rather typical example in this respect is the building of "Palace of Arts", a concert hall in Budapest, which was not accompanied by a preliminary economic analysis of the investment or by cost-benefits analysis of the project. The lack of preliminary planning resulted in additional modifications of the technical characteristics of the building. This has provoked also omissions in the original contract, which led to the renegotiation of its terms and increase of the investment of the public partner to 827 million Euro instead of the initially planned 175 million Euro. Again, due to lack of analysis, in the new contract were not included adjustments of the payment terms associated with the provision of the service as well as update on penalties provisions in case of contract infringement.

\section{Lack of expertise to assess the real capacity}

Financial evaluation of the investment is preceded by the estimation of the capacity of the facility. Lack of expertise for assessing the real capacity in an investment with a view to determining its return rate as well as investment risks assessment is one of the most significant problems in the implementation of PPP. This fact makes it impossible to plan activities and their consequences. Incorrect capacity planning of the built infrastructure as well as wrong estimation for demand of the public service lead to breach of obligations under the contract between the public and private partner. A typical example of complications caused by improper investment planning is the project for the sports hall "Arena Zagreb" in Croatia. According to CEE Bankwatch Network (12), within just a few months - since the beginning of 2009 to July 2009 , the private partner under the project has accumulated obligations up to 600,000 Euro due to incorrect assessment of the capacity demand of the sport hall. Maintenance costs for the hall for 2010 are four times higher than specified in the contract. After the private partner has expressed its intention to close down the hall as of 01.01.2011, the municipality was forced to recover its losses.
Lack of adequate procedures for the selection of partner

Implementation of PPP in Bulgaria requires also improving the procedures for the selection of partner driven by problems with the restriction of competition. The practice of determining the private partner when launching a public-private partnership is by announcing a competitive procedure and collection of offers from interested companies. However, quite often in large infrastructure projects, this practice is not applied. Along with some other investments for roads constructions, the selection of private partner for investment in the highway "Trakia" in Bulgaria is not in result of a competitive procedure. This calls into question the objectivity of the selection, and creates preconditions for suspicion of corruption and attempts to generate private profits at the expense of public expenditure. This fact alone was possible due to existing malpractice and provides proofs for another important deficiency.

\section{Lack of public access to documents for selection}

Restrictions of the public access to documents for preparation and establishment of publicprivate partnership is a significant deficiency in the procedures for PPP related to transparency and sustainability of the investment. Contracts for public-private partnerships are not publicly available because they contain commercial secrets. This makes it difficult for the society to control and correct the quality, conditions and risks in the provision of services related to the public interest. However, despite the contractual terms, as the already mentioned, due to a change of role characteristics through participation in PPP, the public partners are in unfavourable position as society holds them responsible for the availability of the activity/ service of public interest. In this sense, if the private partner fails to comply with its contractual obligations, the public partner is inclined to invest more than planned and renegotiate new terms in favour of the private partner. This fact is a prerequisite for a lower degree of control by the public partner on activities provided. This affects not only Bulgaria but also the countries of Central Europe, where the experience with PPP is relatively small, legal framework is constantly changing as a result of adaptation processes to the European legislation, and no traditions of transparency in the activities of public institutions are available. Given these 
circumstances, the need for higher accountability and transparency in the conclusion of PPP contracts is significant, as it would strengthen the supervision of the contract execution by both parties, and would allow the pursuit of particularistic interests of society in relation to sustainability of investment envisaged, the way of rendering of the public interest activity as well as observation of environmental protection principles.

\section{Lack of control of correlation between resources input and quality}

Another major problem appears to be the discrepancy between invested funds and quality of the service provided. A typical example of this discrepancy is the concession of "Sofia water" AD with Municipality of Sofia, Bulgaria. The concession contract was signed in 2000. In December 2000, the State Committee for Electricity and Water Supply Regulation (DKEVR) has granted a credit to the private company in the amount of 31 million Euro for the purpose of rehabilitation of the water supply network and water filtration. Until the time-point of replacement of the private partner in 2010, water losses in the supply network amounted to $58 \%$ (according to DKEVR).

\section{Lack of reliable mechanisms for risk transfer}

One of the main reasons for implementing PPP is the possibility to transfer the risk from the public to the private partner. The lack of reliable mechanisms for risk assessment leads to its incorrect evaluation and its improper distribution between partners. Besides, there are risks that are not covered by the agreed terms. An example of this is the risk of the occurrence of the financial and economic crisis which, on the one hand, may worsen the situation of the private investor if the investment establishment was arranged by credit; on the other hand, it may have an impact on the demand for the activities provided. Similar force majeure requires commitment by the public financial support to the efforts of the private partner to optimize investment costs without infringement of the contract provisions.

\section{Lack of precise definition of risk management rules}

Management of public-private partnership risks requires precise formulation of the rules between the two parties, and specification of mechanisms for their implementation. For example, risk management related to service
DECHEV D.

availability should include optimization of operating expenses by the private partner, which in turn would be of public interest. Notwithstanding this apparent causal relationship, the Law on public-private partnership in the country does not provide incentives to encourage the optimization of operating costs, but on the contrary, provides financial support to the private partner with which it can cover its operating costs by a guaranteed rate of profit.

\section{Options to renegotiate}

The cases as described above show a significant disadvantage when negotiating PPP, namely the option of renegotiation, which leads to the possibility of transferring the risk. In the case of the D1 motorway in Slovakia, in result of four reviews of the PPP contract, the financial commitments of the public partner rose to 9.128 billion Euro, at an initial value of 7.822 billion Euros.

The main conclusions that can be made as a result of study of several key public-private partnerships in Central and Eastern Europe are in the direction of a negative assessment of the experience in PPP until now. This experience is characterized by a number of problems associated with the lack of planning and an objective assessment of the efficiency of investment, lack of competitive conditions, lack of transparency and effective legislation in order to avoid abuses, and lack of clear procedures for contract negotiation and implementation.

This experience brings rather more negative consequences for public partner. Seriousness of the problems that accompany PPP in the region requires the application of streamlined prevention measures towards malpractices, and creating a secure and stable regulatory environment for public-private agreements in public interest.

\section{What is the actual value of the PPP}

It is defined more by the risks involved in the project than by the cost of building and maintenance of the infrastructure. The private sector assesses these risks in the value of the investment that it is ready to make, i.e. the private sector calculates risks in the investment price, and calculates its efficiency, taking into account these risks. When the state invests, these risks are borne virtually by taxpayers because in most of the cases they are not calculated in the cost of the public debt. These 
different approaches are the result of differences in the definition of priorities.

In practice, long-term commitments of governments under PPP contracts may lead to much higher costs for the public partner compared to the costs that the government would encounter for this investment without a private partner. The will of governments to avoid high deficit and high public debt at the time of the investment might lead to a serious burden to the state budget in the period of the PPP contract duration, drastically increasing the cost of the actual investment and maintenance costs of assets. In this context is also the conclusion of the OECD (13) in terms of PPP which can be significantly more expensive due to differences in the cost of borrowed funds provided to private companies, and public debt.

Evaluation of investment efficiency raises also questions about the quality of service provided and the assessment of value for money. Although there is no precise definition of value for money in the context of PPP, one of the recommendations of the $\mathrm{EU}$ is to use the benchmark "public sector." This indicator compares project value subject to a PPP with the value of this project if it would be performed as a public investment. Unfortunately, this indicator is rarely used in the economic and financial assessment of PPP in the countries in Central and Eastern Europe.

PPP has to combine the advantages of public and private sector, and to neutralize their weaknesses. In this sense, the private partner must acquire social responsibility, while the public sector - management culture. From what has been said above, the successful PPP shall be preceded by four major decisions: 1) a decision on the period of action; 2) a decision on efficiency; 3) decision in terms of management; 4) a decision on payment.

According to the above drawn up analysis, the fundamental criteria to be met by the successful PPP are the following four: efficiency, equity, sustainability and security. Each of these criteria is a set of critical factors to ensure the success of PPP, and for achievement of balance between public and private partners.

Efficiency includes economic evaluation of investment by analysing the costs and benefits of the project, determination of the profit for the private partner and the financial commitments of both parties as well as
DECHEV D.

assurance of accountability and transparency in the implementation of commitments.

Equity refers to the provision of equal and free access to the public resources or infrastructure. The aim is to prevent economic marginalization of certain groups of the society, discrimination and social tension. Under this criterion fall also the degree of transparency of the terms agreed between the parties; opportunity for public discussion; reflection of social opinion and attitudes towards the service or infrastructure that is subject to PPP.

Sustainability in the implementation of PPP must ensure the protection of existing assets, observation of environmental protection principles as well as create conditions for public service adaptation to changes in technology and innovation in the field. The principle of sustainability of the PPP investment means that it shall be adapted to the national development strategy. This suggests effective project management system for the entire period of the contract, risk management system and cash-flow management system.

Security relates to the institutional, political and social stability, which is important for the private partner, and assumes predictability and transparency of the public partner's activity. On the other hand, this criterion relates to the security of stability in international aspect. Onset of the global financial crisis is one of the reasons for unpredictable price increase of PPP projects started, which requires renegotiation of terms, and in some cases suspension of the investment. This is proof that the security in the situation of both the public and private partners is essential for successful implementation of the partnership.

\section{CONCLUSION}

As a result of conclusions drawn up about the problems of public-private partnerships, some recommendations can be summarized in order to improve the environment for PPP and enhance efficiency of this type of cooperation, such as:

- Improvement of procedures for the selection of a partner by creating conditions for effective competition;

- Introduction of expertise for assessing the real capacity investment, and evaluation of the correlation between funds invested and quality;

- Elimination of the possibility of renegotiation for risk transfer from one party to the other; 
- Implementation of mandatory independent economic and financial evaluation of the investment whereby costs involved to be shared among the partners in accordance with their participation;

- Enforce automatic adaptation of the contract in case of future legislative changes in the field;

- Commitment of public financial support to the efforts of the private partner in order to optimize investment costs without infringement of contract provisions;

- Planning for sharing profits earned by the private partner as a result of refinancing debt related to the implementation of the investment;

- Public access to documents for the preparation and establishment of publicprivate partnership;

- Specification of the upper limit of payments under PPP eligible for a public institution, within one year;

- Mandatory penalty provisions for both parties in case of contract infringement;

- Mandatory compliance with the 4 criteria for successful PPP.

Public-private partnership as a way of achieving goals under the terms of efficiency, stability, security and sustainability in the implementation of projects proved to be necessity, and has gained on practicing. Risk reduction and reporting of weaknesses of past experience create prerequisites for its improvement and subsequent implementation in the global world environment.

Despite the risks involved, the public-private partnership model has proved its existence, offering flexible opportunities to quality improvement and provision of various infrastructural projects with related public services.

\section{REFERENCES}

1. Pfnür et al., Risikomanagement bei Public Private Partnerships, DOI 10.1007/978-3642-01073-6_3, Springer-Verlag Berlin Heidelberg 2010

2. Business, (PIEB), issue: 3(3)/2009, pages: 25-28:

http://ideas.repec.Org/a/pdc/jrpieb/v 3y2009i3p25-28.html.

3. Miller J.,Applying multiple project procurement methods to a portfolio of infrastructure projects, in Procurement systems: A guide to best practice in construction, E 8t N Spon. 1999:
DECHEV D.

4. IMF 2004: Public-Private Partnerships, prepared by the Fiscal Affairs Department (in consultation with other departments, the World

5. Law on Public-Private Partnership, promulgated in SG 45 as of 15.06.2012, effective as of 01.01.2013, amended in SG 87 from 9.11.2012, effective as of 01.01.2013, supplemented in SG 102 from 21.12.2012, effective as of 01.01.2013, Art. 3(1) http://www.minfin.bg/document/11839:1

6. Hall D., 2004: PPPs: a critique of the Green Paper, Public Services International Research Unit (PSIRU), University of Greenwich, London, 2004, $\mathrm{p}$

7. http://www.minfin.bg/bg/page/523

8. Urio P., 2010: Under What Conditions Can Public-Private Partnerships (PPPs) Improve Efficiency, Equity, Security and Sustainable Development in Countries at the Pre-PPP Stage?, p. 29, in Public-Private Partnerships Success and Failure Factors for InTransition Countries, edited by Paolo Urio, 2010.

9. CEE Bankwatch Network, 2008: Nevermind the balance sheet: The dangers posed by publicprivate partnerships in central and eastern Europe, November 2008: <http://bankwatch.org/documents/never_mi nd_the_balance_sheet.pdf

10.Urio P., 2010: Under What Conditions Can Public-Private Partnerships (PPPs) Improve Efficiency, Equity, Security and Sustainable Development in Countries at the Pre-PPP Stage?, in Public-Private Partnerships Success and Failure Factors for InTransition Countries, edited by Paolo Urio, 2010

11.Pfnür et al., Risikomanagement bei Public Private Partnerships, DOI 10.1007/978-3642-01073-6_3, Springer-Verlag Berlin Heidelberg 2010

12.CEE Bankwatch Network, 2008: Never mind the balance sheet: The dangers posed by public- private partnerships in central and Eastern Europe, November 2008: $<$ http://bankwatch.org/documents/never_mi nd_the_balance_sheet.pdf $>$.

13.OECD, 2006: Infrastructure to 2030: Main findings and Policy recommendations, OECD Futures Project on „Global Infrastructure Needs: Prospects and Implications for Public and Private Actors", 2006: <http://www.iva.se/upload/Verksamhet/Pro jekt/Forskning\%20lnnovation/ Bibliotek/OECDJong.pdf 